\title{
Neuroblastoma Grafts Are Noninvasively Removed within Mouse Neocortex by Selective Laser Activation of Intracellular Photolytic Chromophore
}

\author{
Jeffrey D. Macklis ${ }^{1}$ and Roger D. Madison ${ }^{2}$ \\ ${ }^{1}$ Department of Neurology and Program in Neuroscience, Harvard Medical School and Mental Retardation Research \\ Center, The Children's Hospital, Boston, Massachusetts 02115 and 'Division of Neurosurgery, Duke University Medical \\ Center and Research Service, Veterans Administration Medical Center, Durham, North Carolina 27710
}

\begin{abstract}
Studies of neural cell transplantation would be aided by the ability to damage or destroy, noninvasively and extremely selectively, grafted cells at defined times following their Initial implantation. Mechanisms of graft integration and performance could be investigated, also providing insight into natural injury and repair mechanisms. At long wavelengths between 650 and $850 \mathrm{~nm}$, laser energy can penetrate several millimeters of brain tissue without absorption or damage to the unpigmented tissue. However, targeted cells are selectively damaged by. illumination at these long wavelengths if they contain latex nanospheres with incorporated cytolytic chromophores (e.g., chlorin $e_{6}$ ). Light penetration allows many thousands of cells to be lesioned simultaneously, noninvasively, and deep within a surrounding matrix of other tissue. Such laser-activated damage has been termed laser photolysis (PL).
\end{abstract}

We studied damage to $C_{1300}$ neuroblastoma (NB) cells grafted into mouse neocortex in vivo by this process of PL. NB cells provided a simple and reproducible model of neural grafting, allowing direct histologic assessment of cellular growth and viability by distinct morphologic and mitotic criteria. Cells were cultured by standard methods, labeled in vitro by brief exposure to nanospheres containing chlorin $e_{6}$, and grafted to sites within deep layers of mouse neocortex. Mice were exposed to transcranial, fractionated, unfocused pulses of 670-nm-wavelength energy totaling $90-120 \mathrm{~J} / \mathrm{cm}^{2}$. We histologically assessed graft growth and cellular viability over a period from $2 \mathrm{~d}$ to 4 weeks, measured graft volumes quantitatively during the period of early rapid growth in controls ( 2 and $7 \mathrm{~d}$ ), and generated 3-D reconstructions from serial sections to assist in visual analysis.

NB grafts that were prelabeled and exposed to transcranial laser energy sustained dramatic loss of cellular viability and an average reduction in graft volume of approximately $90 \%$ by $7 \mathrm{~d}$. These lesioned grafts were largely devold of NB cells, composed primarily of inflammatory cells and degenerating NB cells. Controls were unaffected by either pre-

\footnotetext{
Received Aug. 16, 1990; revised Feb. 1, 1991; accepted Feb. 5, 1991.

This work was supported by U.S. Public Health Service Grants HD00859 to J.D.M. and NS22404 to R.D.M. and Mental Retardation Center Grant HD18655 and by grants from the Alzheimer's Association to J.D.M. and from the Whitaker Foundation to R.D.M. and J.D.M. We wish to thank Bruce Bonsack for excellent technical assistance and Nancy Forman for preparation of the manuscript.

Correspondence should be addressed to Jeffrey D. Macklis, Enders 386, The Children's Hospital, 320 Longwood Avenue, Boston, MA 02115.

Copyright (C) 1991 Society for Neuroscience $0270-6474 / 91 / 112055-08 \$ 03.00 / 0$
}

labeling or laser illumination atone, and tissue surrounding lesioned grafts remained undamaged histologically. Our results show that cells can be labeled in vitro, grafted in vivo to mouse cortex, and selectively damaged by subsequent exposure to noninvasive, unfocused laser illumination. These results suggest that prelabeled neurons could be noninvasively removed following transplantation into rodent CNS, with selectivity for both cell type and geographic location, as a rigorous test of functional integration and performance. The findings also demonstrate the possibility of selectively targeting neuronal subpopulations or isolated nuclei in vivo for laser lesioning. Such selective lesioning may allow a new level of precision in "dissecting" elements of functional CNS anatomy. The use of such selectively neuron-deficient degeneration models as hosts for neuronal transplantation may allow significant control over both host and graft conditions.

Studies have shown that grafted nervous system tissue can repair structural damage following lesions, form host-graft connections, and partially or fully restore depleted neurotransmitter levels (Bjorklund et al., 1982; 1984; Kromer et al., 1983; Bjorklund and Stenevi, 1984; Reier, 1985; Stanfield and O'Leary, 1985; Sotelo and Alvarado-Mallart, 1986, 1987; Gage et al., 1987; Kamo et al., 1987; Raisman et al., 1987; Goldberg and Bernstein, 1988). Neural grafting has effected functional improvement in lesioned animals in selected situations, but the mechanisms of this response are not yet clearly understood in many experimental paradigms (Gage et al., 1984a; Brundin et al., 1986; Sladek et al., 1987; Lee et al., 1988; Goetz et al., 1989)

Possible effects of grafting include surgical lesions to antagonist systems from the grafting procedure itself, introduction of trophic factors within the graft, activation of endogenous trophic factors within the host, and breakdown of the blood-brain barrier (Freed, 1983; Gage et al., 1984b; Nietro-Sampedro et al., 1984; Eclancher et al., 1985; Gibbs and Cotman, 1987; Kromer, 1987; Rosenstein, 1987; Rosenberg et al., 1988). Rigorous tests would be useful to determine functional integration of grafted tissue. Ideally, such tests would aid both in evaluating graft efficacy and in understanding natural mechanisms of injury and repair. The mechanism of graft integration could be carefully determined by the ability to remove or damage, noninvasively and selectively, grafted cells at desired times and in a graded manner. We have begun to exploit methods by which grafted neurons or neural cells can be noninvasively lesioned within the 
rodent CNS to address such questions of functional integration of grafted neurons. This selective damage takes place without injury to intermixed neurons, glia, axons, or vascular and connective tissue.

Miller and Selverston (1979) were the first to describe the general technique of photodamaging cells via injection of fluorescent dyes and subsequent exposure to focused fluorescent light. Subsequent investigators have used focused light to lesion individual neurons in vitro or individual developmentally important cells in developing invertebrates and vertebrates, with or without intracellular fluorescent dye (Cohan et al., 1982; Hibbard and Erlich, 1982; Kater and Hadley, 1982; Bently and Caudy, 1983; Kaper et al., 1984; Eisen et al., 1989). There are limitations to lesioning techniques using focused fluorescent or laser light. Fluorescent light or focused laser light themselves can cause damage to cells, and wavelengths of light suitable for excitation of most fluorescent dyes (i.e., $<500 \mathrm{~nm}$ ) penetrate mammalian tissue very poorly, limited to the most superficial cell layers (Anderson and Parrish, 1981a; Wan et al., 1981). Damage to tissue in vivo is necessarily limited by the use of the relatively short wavelengths of fluorescent light to very superficial targets. Therefore, only "line-of-sight" surface cells can be lesioned, and care must be taken not to expose surrounding cells to the fluorescent or focused laser light to guard against nonspecific damage.

Light does not penetrate well through mammalian soft tissue at the wavelengths used to excite most fluorescent dyes (i.e., $300-600 \mathrm{~nm})$. This is due to absorbance by the major endogenous chromophores, melanin and hemoglobin. A series of elegant studies within the field of dermatology by Anderson and Parrish $(1981 \mathrm{~b}, 1983)$ took advantage of the high degrec of absorption of these endogenous chromophores to cause selective thermal damage to endogenously pigmented structures. Short pulses of unfocused, high-energy illumination were shown to damage microvessels selectively, leaving "nearest-neighbor" cells intact. Even shorter pulses at a different wavelength were used to destroy melanosomes, leaving the parent melanocytes intact. This thermal damage to microvessels or melanosomes took place at depths of several millimeters beneath the surface of the skin. The overlying epidermis and dermis sustained no observable damage in these experiments.

It was predicted by this previous work with endogenously pigmented tissue that exquisitely specific thermal damage could be obtained with selective photolysis (PL), to targeted neuronal subpopulations embedded within a 3-D matrix of other tissues, utilizing exogenous chromophores selectively delivered to target cells. In order to develop selective lesioning techniques for use in vivo with deep structures, for example, deep CNS nuclei, one must exploit the deep penetration of near-infrared light (650850 -nm wavelength) through soft tissue. In contrast to the shorter wavelengths of light discussed above, absorption by the major endogenous chromophores, melanin and hemoglobin, is markedly reduced at these relatively longer wavelengths of light. Laser light at these wavelengths penetrates effectively several millimeters through mammalian tissue, delivering up to megawatts of energy without significant nonspecific absorption or damage (Anderson and Parrish, 1981a; Wan et al., 1981). These results suggest that sufficient energy of near-infrared wavelengths of light penetrates through rodent tissue to effect damage by selective PL anywhere within the rodent CNS, if cells can be labeled with sufficient exogenous chromophore.

PL can also be affected by singlet oxygen $\left({ }^{1} \mathrm{O}_{2}\right)$ mechanisms, producing cellular damage by illumination within this "optical window" in the near-infrared range. Light-activated molecules (photosensitizers) may be selectively targeted to appropriate subpopulations of cells, producing no ${ }^{1} \mathrm{O}_{2}$, and no cellular injury, prior to specific wavelength illumination (Berns, 1984). This toxic molecule has a diffusion range of approximately $0.1-0.2$ $\mu \mathrm{m}$. Damage by $\mathrm{PL}$ via ${ }^{\prime} \mathrm{O}_{2}$ is thought to be secondary to membrane disruption at the cell, organelle, or lysosomal level.

Our previous in vitro studies demonstrated the efficacy of targeted exogenous chromophores to effect selective damage in vitro. We produced dose-dependent damage using thermal and singlet oxygen PL to cultured dorsal root ganglion neurons, neocortical neurons, and neuroblastoma (NB) cell lines (Macklis and Madison, 1985; Madison et al., 1988; Madison and Macklis, 1989). These studies demonstrated that, following selective labeling with appropriate chromophores, specific cellular damage could be produced with short, high-energy laser pulses in the 660-700-nm-wavelength range. This damage was found to be dependent on both the intracellular chromophore concentration and the dose of incident laser energy. Selective PL has been demonstrated for human $\mathrm{T}$-cells in vitro targeted by conjugates of a photosensitizing dye attached to monoclonal antibodies (Oseroff et al., 1986). The singlet-oxygen-producing photosensitizer used in these studies was chlorin $e_{6}$, a photostable, nontoxic, highly effective producer of ${ }^{1} \mathrm{O}_{2}$.

PL allows a two-stage selectivity. First, nontoxic agents are delivered relatively specifically to targeted populations. Added specificity is then achieved by geographic localization of laser illumination. In contrast, even the most highly specific targeting of cytotoxic agents invariably causes undesirable, nonspecific damage secondary to tissuc cross-reactivity in the targeting phase and to local toxic effects on neighboring cells. There is no need to focus the laser energy optically to target cells via PL, other than to ensure that sufficient energy arrives within the area containing the target cells. Selective damage to labeled cells is possible, as long as there is an adequate concentration of exogenous dye absorbing at the wavelength of the laser in use, and as long as the wavelength is one not absorbed significantly by normal tissue. Damage by PL is quite different from existent methods for effecting cellular damage using laser microbeams, fluorescent dye injections, or focused fluorescent beams. The localization of damage can be as precise as with microbeam techniques, but thousands to millions of targets can be damaged simultaneously without precise aiming.

The in vitro studies described above suggested the need to develop concentrated carriers of exogenous chromophores (absorbing in the $650-850-\mathrm{nm}$ range), capable of delivering high concentrations of either thermal dyes or ${ }^{1} \mathrm{O}_{2}$ generators to subpopulations of neurons in vivo. We developed a latex nanosphere delivery system (LNDS) that is capable of carrying high concentrations of desired chromophores (Madison et al., 1990). The particular polymers used are resistant to degradation and are biocompatible. Similar particles have been shown to become localized indefinitely within cytoplasmic lysosomal storage granules (Quattrochi et al., 1987), and the LNDS particles used in the present studies remain visible by fluorescence microscopy and can be localized by electron microscopy within cytoplasmic granules for periods greater than 1 yr (J. D. Macklis, unpublished observations). A wide range of dyes can be incorporated within LNDS particles, including the nontoxic chlorin $e_{6}$ as a ${ }^{1} \mathrm{O}_{2}$ producer. An absorption peak in the near-infrared range (660-670 $\mathrm{nm}$ ) makes chlorin $e_{6}$ a suitable ${ }^{1} \mathrm{O}_{2}$ generator for $\mathrm{PL}$ in vivo. 
Chlorin $e_{6}$ has a molar extinction coefficient of approximately $59,000 \mathrm{M}^{-1} \cdot \mathrm{cm}^{-1}$ at $670 \mathrm{~nm}$. By comparison, the extensively studied photosensitizer hematoporphyrin derivative (HPD) has only $1-10 \%$ this amount of absorption at near-infrared wavelengths (Berns, 1984). Chlorin $e_{6}$ also offers superb photostability, with less than $20 \%$ bleaching after exposure to $50 \mathrm{~J} / \mathrm{cm}^{2}$ in the 660-670-nm range (Oseroff et al., 1986; Madison and Macklis, 1989); it continues to produce singlet oxygen even after continual illumination over long periods of time.

Chlorin $e_{6}$ is permanently incorporated into nanospheres and does not diffuse out of the polymer base. Ready diffusion of aqueous species within the nanospheres allows availability of singlet oxygen produced anywhere within the nanospheres. Long survival times do not have the problem of nonselective labeling from widespread diffusion of the chromophore into surrounding tissues because the nanospheres do not diffuse significantly at the injection site or from labeled cells (Madison et al., 1990; Macklis and Quattrochi, 1991).

Relatively large variation in the intensity of neuronal labeling does not pose a practical problem for cellular lesioning due to the wide range and flexibility of laser and dye dose-response curves for production of irreversible cellular damage (Madison et al., 1988; Madison and Macklis, 1989). Targeted neurons in vitro with intracellular chromophore concentrations varying over approximately two to three orders of magnitude underwent irreversible cellular injury over periods of $30 \mathrm{sec}$ to $24 \mathrm{hr}$, inversely proportionate to chromophore concentration. As long as a threshold level of labeling is present, sufficient damage results to kill targeted neurons. Greater levels of labeling result in more rapid damage, but if such damage occurs over minutes to days, it occurs within the tissue's ability to dispose of cellular debris effectively.

We report here selective, noninvasive lesioning of prelabeled, grafted NB cells within mouse neocortex in vivo. NB cells were used to test this approach because they allow direct histologic assessment of graft injury by their distinct appearance using routine staining methods. Labeling in vitro allowed control over intracellular chromophore concentration, approximately matching concentrations possible with dissociated neocortical neurons. Reproducible growth of control NB graft tumors provided a well-defined measure of NB cellular viability and survival.

\section{Materials and Methods}

Neuroblastoma cultures and in vitro labeling. Neuroblastoma cells from the mouse $\mathrm{C} 1300$ line (type NB41A3, American Type Culture Collection) were serially passaged in monolayer cultures. Aliquots of cells were stored from confluent cultures by slow freezing in F-10 medium (Gibco) in the presence of $8 \%$ dimethyl sulfoxide (DMSO) as a cryoprotectant. Cells were grown in $\mathrm{F}-10$ medium supplemented with $15 \%$ horse serum and $2.5 \%$ fetal bovine serum. Cultures were maintained at $37^{\circ} \mathrm{C}$ in $5 \%$ $\mathrm{CO}_{2}$, medium was changed twice weekly, and cells were passaged when they became fully confluent. Cells were used for grafting experiments when $60-80 \%$ confluent.

Neuroblastoma cultures were exposed to latex nanospheres with incorporated chlorin $e_{6}$ as a singlet oxygen producer and rhodamine as a fluorescent intracellular label; nanospheres were added at a concentration of $20 \mu \mathrm{l} / \mathrm{ml}$ for $4 \mathrm{hr}$ at $37^{\circ} \mathrm{C}$. Cultures were washed three times with fresh medium and allowed to incorporate fully the nanospheres overnight at $37^{\circ} \mathrm{C}$. Labeled cells were exposed to $1 \mathrm{ml}$ of $0.25 \%$ trypsin for 1-3 min, suspended into $3-4 \mathrm{ml}$ of fresh medium, gently triturated, washed three times, and pelleted by low speed centrifugation ( $5 \mathrm{~min}$ at $1000 \mathrm{rpm}$ ) to a final cell concentration of $1-2 \times 10^{4}$ cells $/ \mu \mathrm{l}$.

In vivo grafting. Fifty-six male $\mathrm{C} 57 \mathrm{~B} / 6 \mathrm{~J}$ mice, $8-10$ weeks old, served as hosts for grafting of control or prelabeled neuroblastoma cells within the neocortex. Mice were deeply anesthetized, and the skin overlying the skull was incised and reflected bilaterally. Triangular "windows" of skull $\left(4-8 \mathrm{~mm}^{2}\right)$ were temporarily removed, approximately $1-2 \mathrm{~mm}$ lateral and 1-2 mm posterior to bregma unilaterally or bilaterally. Cells were slowly pressure injected $(0.25 \mu \mathrm{l}$ over $10 \mathrm{~min})$ unilaterally or bilaterally using a motorized syringe pump (Sage Instruments, model 341) and microliter syringe attached to pulled-glass micropipettes. The micropipettes were positioned for injection $500-800 \mu \mathrm{m}$ below the surface (within deep cortical layers). The skull "windows" were replaced, and the overlying skin was closed. Control studies were performed to compare the growth of prelabeled and unlabeled NB grafts, and to compare the growth of unilateral and bilateral grafts.

Laser exposure. Mice were exposed to unilateral laser illumination over the region of one of the grafts $24 \mathrm{hr}$ following grafting of control or prelabeled neuroblastoma cells. Control experiments assessed the effects of laser exposure on grafts of unlabeled NB cells. Contralateral hemispheres served as additional controls, in bilaterally grafted experimental mice, for labeled NB injection and growth without laser exposure under identical systemic conditions. Mice were deeply anesthetized, and skin overlying a previously closed skull window was reflected laterally, without removing the bone itself. A tunable dye laser (Candela, MPDL-500) delivered 300-nsec pulses of 670-nm light at a repetition rate of $0.1 \mathrm{~Hz}$ through a $1-\mathrm{mm}$ flexible quartz fiber. Total surface energy doses of $90-120 \mathrm{~J} / \mathrm{cm}^{2}$ were delivered over exposure areas $3 \mathrm{~mm}$ in diameter with 180 pulses during single 30 -min sessions. Following exposure, overlying skin was closed, and mice were returned to standard care.

Histological techniques. Survival times for histological analysis ranged from $2 \mathrm{hr}$ to 4 weeks following neuroblastoma grafting. Mice were deeply anesthetized, transcardially perfused with $2 \%$ paraformaldehyde in a $0.1-\mathrm{M}$ phosphate buffer ( $\mathrm{pH}, 7.3-7.4)$, and postfixed overnight in the same fixative. Brains were blocked for coronal sectioning, and serial sections $40 \mu \mathrm{m}$ thick were cut through the regions of interest on a vibrating microtome. Alternate third sections were stained and mounted for fluorescence, cresyl violet (CV), or hematoxylin and eosin (H\&E), respectively. Analysis included NB cell labeling, graft growth and size, host reaction, NB cellular morphology, and density of viable and degenerated NB cells. Quantitative area and cell density measurements were performed from $\mathrm{CV}$ and $\mathrm{H} \& \mathrm{E}$ sections, using a video-based image analysis system (Hamamatsu, Argus 10) to calculate areas of abnormal cellular morphology manually outlined from glass slides, and to tally distinct morphologic subtypes identified by direct microscopy. Outlines and measurements were determined by two independent observers, blinded to the origin of each sample. Standard contrast values on live video images were used to determine the borders of NB grafts and intermixed inflammatory cell infiltrate. Measurements were repeated by each observer twice to assure reproducibility, and comparisons were made between the measurements of the two observers. Volume calculations were made from averages of the area measurements from cach stained section, multiplied by the section thicknesses $(40 \mu \mathrm{m})$, interpolating the areas for unstained, fluorescence sections from adjacent sections. Volume analysis was performed for four matched experimental and control hemispheres at $2 \mathrm{~d}$ and at $7 \mathrm{~d}$ following NB grafting.

We reconstructed three-dimensional images of two typical brains containing control and experimental NB grafts solely to aid in visual analysis. No quantitative analysis was performed from these reconstructions, and histologic assessments were made from direct microscopic observations of stained sections. Serial $C V$ and $H \& E$ sections were used to enter digitized section and graft outlines into a VAX-based DEC graphics display system (Image Graphics Laboratory, The Children's Hospital). Reconstructions in three dimensions were computed, rotated for analysis, and used to capture partial reconstruction images showing relevant visual details comparing experimental and control hemispheres. Section thickness was used to scale the reconstructions appropriately.

\section{Results}

NB cultures that were labeled with nanospheres containing chlorin $e_{6}$ remained healthy and continued to divide normally in vitro. Cultures were followed and passaged for 4 weeks, the duration of the parallel experiments in vivo, with excellent viability and growth. Cells were observed to contain varying levels of intracellular, granular fluorescence provided by the nano- 

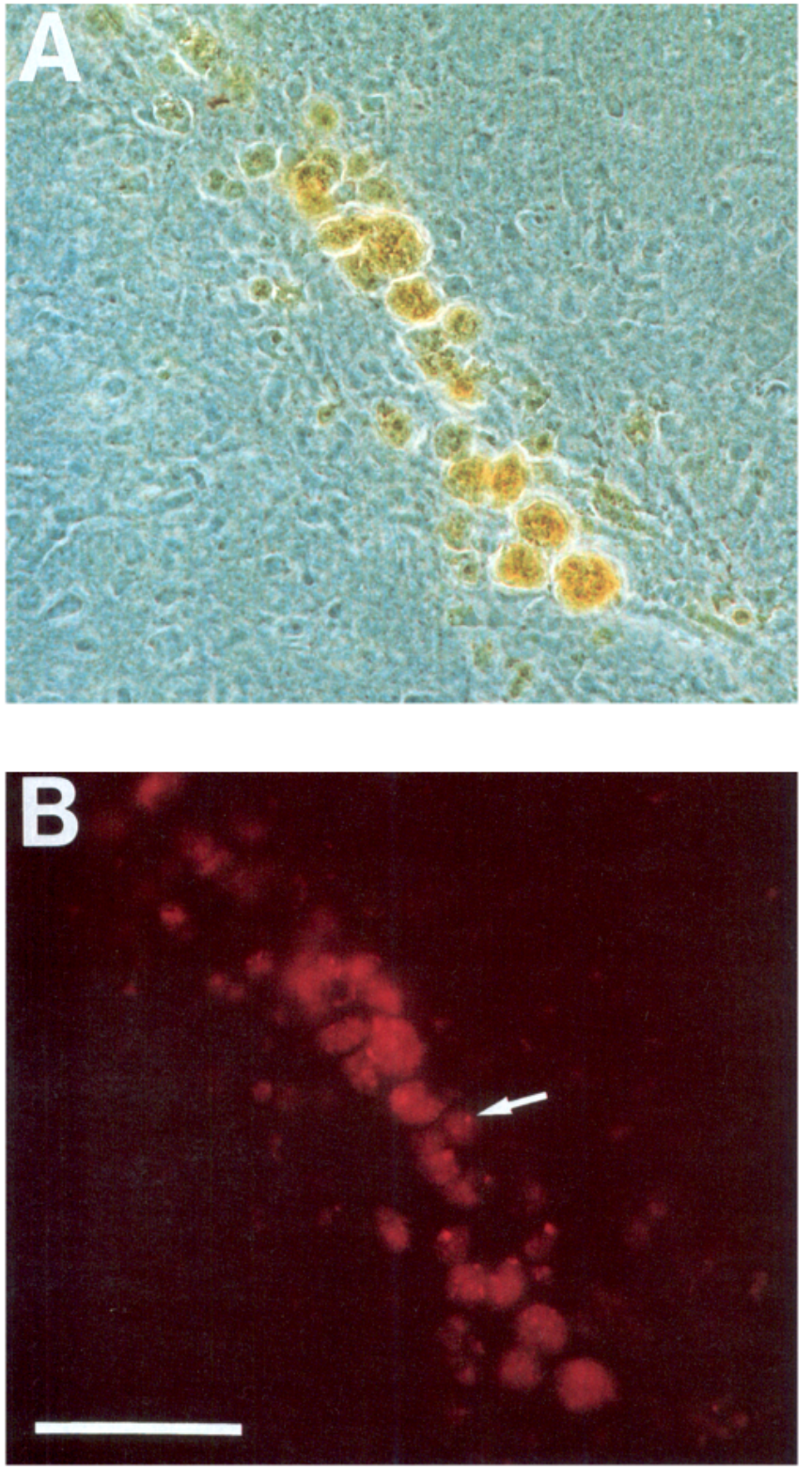

Figure 1. Grafted NB cells labeled in vitro with latex nanospheres containing chlorin $e_{6}$ as a singlet oxygen producer and rhodamine as a fluorochrome. Cultured cells were resuspended and used for grafting into mouse neocortex in vivo. $A$, Phase-contrast appearance of labeled NB cells within unstained $50-\mu \mathrm{m}$ section of neocortex $1 \mathrm{~d}$ following labeling and grafting. $B$, Fluorescence appearance of the same field, with NB cells in the plane of focus displaying punctate, granular cytoplasmic fluorescence (arrow). Scale bar, $50 \mu \mathrm{m}$.

spheres that contained a second, fluorescent chromophore (rhodamine) incorporated for visual identification. Although intracellular granular labeling was observed to decrease in intensity with successive cell divisions, labeling remained brightly visible during the first week. The range of labeling intensities coincided with those seen in previous selective lesioning studies in vitro, in which cell lysis occurred over a range of times from minutes to many hours with targeted dorsal root ganglia neurons (Macklis and Madison, 1985; Madison et al., 1988) or NB cells and neocortical neurons (Madison and Macklis, 1989). Laser energy alone or intracellular labeling alone produced no injury to control cells in those studies.

No difference was seen in growth and survival in vivo between NB cell grafts without LNDS label $(n=13)$ or with LNDS labeling prior to grafting $(n=27)$ in preliminary control experiments. Labeled NB cells could be easily identified using either phase-contrast or fluorescence microscopy (Fig. 1), and intracellular fluorescence was observed to span a similar range of intensity as that seen in vitro. No difference was present in the typical size of the grafts or in appearance of grafted NB cells or surrounding host tissue at 2-4 hr, 2-3 d, 1 week, 2 weeks, or 4 weeks, as assessed by $\mathrm{CV}$ and $\mathrm{H} \& \mathrm{E}$ sections. The appearance and size of NB grafts were quite reproducible at each of the times from $2 \mathrm{hr}$ to 1 week, with the most dramatic growth seen between 2 and $7 \mathrm{~d}$. Variable amounts of compression were evident to ventricles and surrounding structures between 2 and 4 weeks, so the period between 2 and $7 \mathrm{~d}$ was chosen for study to assure reproducibility. No difference was seen between bilateral or unilateral cell grafts at times up to 2 weeks.

Control experiments were undertaken to assess the effect of laser exposure alone on NB cell grafts without LNDS prelabeling. These experiments revealed no effect on NB cell growth or surrounding tissue integrity at 2,7 , or $14 \mathrm{~d}(n=6)$. Other studies have also demonstrated the absence of injury to untargeted structures at energies higher than those used in these experiments (Madison and Macklis, 1989; R. D. Madison and J. D. Macklis, unpublished observations). Laser doses up to twice those used in these studies produced no disruption or damage to intermixed axons, neurons, glia, or connective tissue. Identical procedures were used for cell grafting of prelabeled NB cells and laser exposure to bilaterally grafted animals to yield experimental and control hemispheres.

Large NB tumors were found in injected control mice and the unlased hemispheres in experimental mice at $7 \mathrm{~d}(n=4)$ and $14 \mathrm{~d}(n=4)$, with small areas of necrosis present (Fig. $2 B, D)$. Absence or reduction of NB tumor volume was found at 7 and $14 \mathrm{~d}$ in hemispheres containing prelabeled NB cells exposed to laser energy. These experimental hemispheres also displayed degenerated NB "ghost" cells, infiltration by polymorphonuclear leukocytes, lymphocytes, and macrophages, and normal surrounding cellular architecture (Fig. $2 A, C$ ). Surrounding tissue was undamaged by these laser energies. A reduction was found of approximately $90 \%$ in NB tumor volume by quantitative analysis of experimental NB cellular volumes compared with unlased control regions in contralateral hemispheres after $7 \mathrm{~d}$ (6 d after laser exposure). NB cell grafts increased their mean volumes in control hemispheres to $30.3 \pm 12.1 \times 10^{6} \mu \mathrm{m}^{3}$ at

Figure 2. NB grafts prelabeled with nanospheres containing chlorin $e_{6}$ and exposed to transcranial laser illumination sustained dramatic reduction in graft volume and cellular viability. $A$, Prelabeled and laser-illuminated graft displays degenerated NB "ghost" cells, inflammatory cellular infiltrate (arrow), and undamaged surrounding tissue. Scale bar, $200 \mu \mathrm{m}$. B. Labeled, unilluminated control graft in the contralateral hemisphere of the same mouse, at the same magnification as $A$, displays dense cellularity and anaplasia. $C$ and $D$, Higher-magnification views of these experimental and control grafts, respectively. In $C$, indistinct, more lightly blue hematoxylin-stained NB "ghost" cells are evident (long arrow), remaining NB cells show pallor, and polymorphonuclear leukocytes, lymphocytes, and macrophages are present (short arrow). Scale bar, $50 \mu \mathrm{m}$. In $D$, anaplastic NB cells predominate (long arrow), and frequent mitotic figures are seen (short arrow). Same magnification as $C$. 

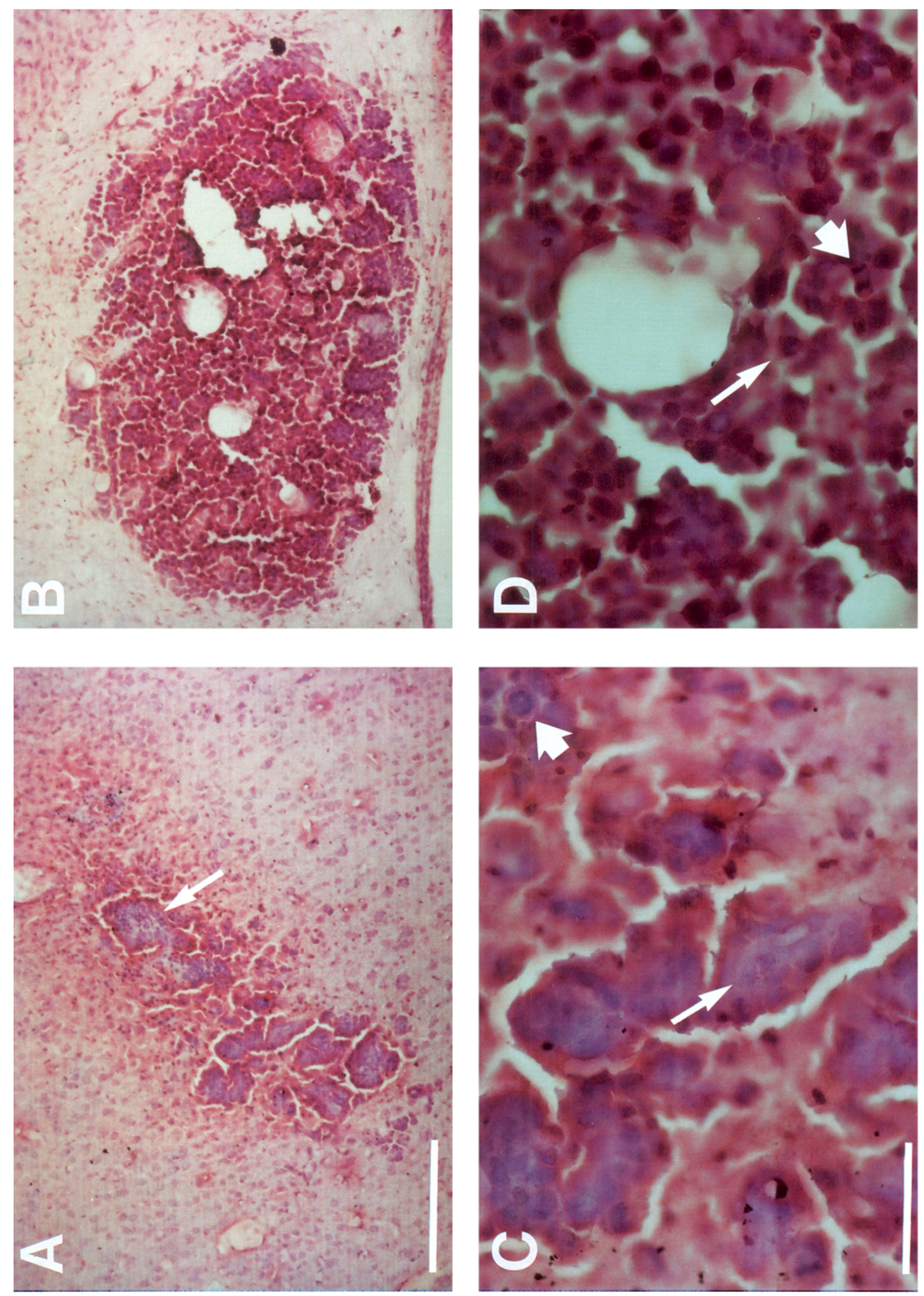


\section{PHOTOLYSIS OF LABELED NB GRAFTS}

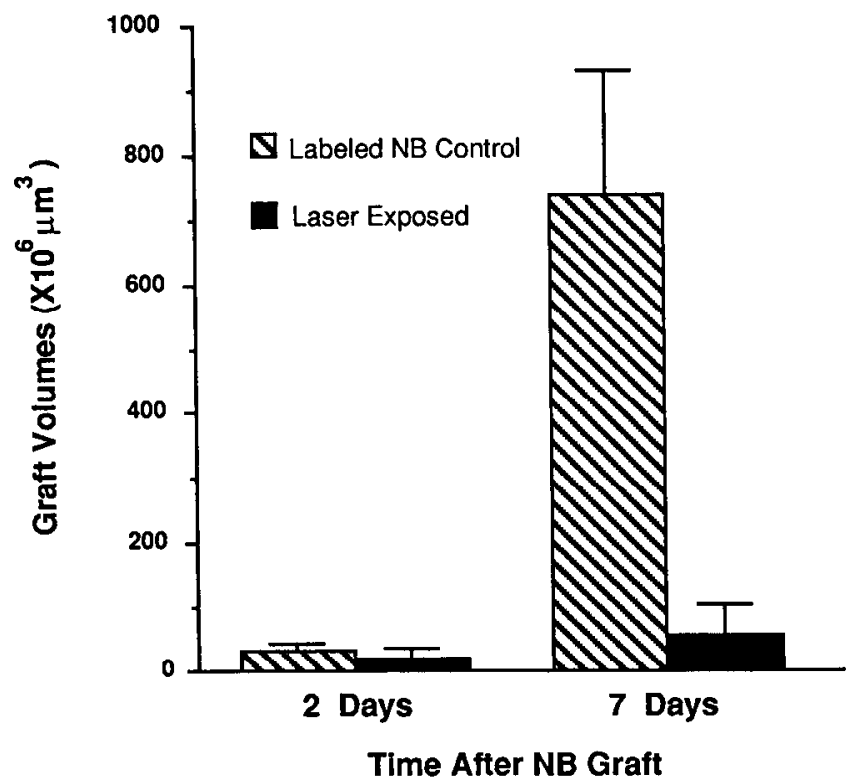

Figure 3. Reduction in volume growth of NB grafts labeled with nanospheres containing chlorin $e_{6}$ and transcranially illuminated with 670$\mathrm{nm}$ laser light. Between $2 \mathrm{~d}$ and $7 \mathrm{~d}$, labeled control grafts expanded dramatically in volume, while laser-illuminated grafts enlarged only slightly, predominantly composed of inflammatory cells and degenerating NB cells ( $n=4$ for each group). Error bars indicate SD.

$2 \mathrm{~d}(n=4)$ and $740 \pm 192 \times 10^{6} \mu \mathrm{m}^{3}$ at $7 \mathrm{~d}(n=4$; Fig. 3$)$. Mean volumes for NB cell grafts in the experimental hemispheres exposed to laser illumination were $21.8 \pm 15.6 \times 10^{6}$ $\mu \mathrm{m}^{3}$ at $2 \mathrm{~d}(n=4)$ and $55.5 \pm 49.8 \times 10^{6} \mu \mathrm{m}^{3}$ at $7 \mathrm{~d}(n=4)$. Measurements were extremely reproducible by any single observer and between observers for areas within individual sections and, therefore, for total NB cellular volume. Interobserver variability ranged between $1 \%$ and $27 \%$ for volume measurement in terms of measurement of individual areas. Variability was typically $<15 \%$, with smaller variability present with larger areas. Area measurements varied by $<1 \%$ to $8 \%$, typically $1-$ $2 \%$, by any single observer.

NB cell survival was dramatically reduced within the regions of NB cellularity of the experimental hemispheres at $7 \mathrm{~d}$, compared with control hemispheres. Within the control hemispheres analyzed on H\&E sections (three sections from each of two mice), distinct, anaplastic, deeply hematoxylin-stained, nucleated NB cells were present at a cellular density of $61 \pm 7$ per $10,000 \mu \mathrm{m}^{2}$ ( $95 \%$ of total NB cells), while indistinct, light blue, degenerated NB "ghost" cells were present at $3 \pm 2$ per 10,000 $\mu \mathrm{m}^{2}(5 \%$ of total NB cells). Experimental hemispheres contained distinct, anaplastic NB cells at densities of $4 \pm 2$ per 10,000 $\mu \mathrm{m}^{2}$ ( $6 \%$ of total NB cells), and NB "ghost" cells, at $63 \pm 6$ per $10,000 \mu \mathrm{m}^{2}$ (94\% of total NB cells). These results, in combination with the greater than $90 \%$ reduction in NB cellular volume, demonstrate that fewer than $1 \%$ of the anaplastic NB cells present in control hemispheres remain in experimental hemispheres $6 \mathrm{~d}$ following selective lesioning by PL.

3-D reconstructions are shown in Figure 4 of serial sections from two representative animals at $7 \mathrm{~d}$ and $14 \mathrm{~d}$. Grafted areas are largely devoid of NB cclls within the hemispheres exposed to laser energy, and indicated volumes are primarily composed of inflammatory infiltrate and degenerated NB "ghost" cells. Control hemispheres, not exposed to laser energy, are almost entirely composed of anaplastic NB cells with active mitosis present and only minimal inflammatory infiltration at the borders of the cell mass, as seen in Figure 2. These control hemispheres displayed vastly larger tumor volumes. The control NB graft shown at $14 \mathrm{~d}$ can be seen to cross the midline and compress the ventricular system; this was a frequent finding in control grafts.

\section{Discussion}

These results suggest that prelabeled neurons can be noninvasively removed following transplantation into rodent $\mathrm{CNS}$, as a rigorous test of their functional integration and performance. Such studies could yield significant insight into the mode of action of transplanted neural tissue by removing the graft long after initial transplantation. The NB cells used in these studies were continuously dividing, so laser exposure was performed only 1 or $2 \mathrm{~d}$ after LNDS labeling. Postmitotic neurons retain undiluted concentrations of LNDS particles within lysosomal granules indefinitely, and thus could be subjected to laser exposure at much later time points.

Several studies have shown the efficacy of using latex or polystyrene microspheres (Katz et al., 1984) to follow neuronal and non-neuronal cells labeled in vitro and then transplanted in vivo (Coulombe and Bronner-Fraser, 1986; Colombo et al., 1987; Emmett et al., 1988). In those studies, the latex particles contained only rhodamine as a fluorescent tracer to allow identification of transplanted cells from host cells. In our present studies with prelabeled NB cells, the LNDS particles contained both a fluorescent tracer (rhodamine) and a singlet oxygen producer (chlorin $e_{6}$ ). This double labeling allowed both the anatomical identification of grafted cells and the ability to damage selectively only the NB cells while leaving surrounding tissue intact.

All transplanted cell types were labeled by the particles used in the studies mentioned above, non-neuronal as well as neuronal. Recent work from our laboratories has shown the ability of specific LNDS particles to undergo differential uptake by neurons due to surface charge of the particles or the surface attachment of specific lectins (Madison et al., 1990). Although the current use did not necessitate selective uptake of LNDS particles to effect PL of grafted NB cells, this characteristic suggests the possibility of selective labeling of a specific cell population in vitro with the subsequent removal of only that cell type. For instance, it should be possible to label predominantly neuronal cells in a mixed culture containing neurons and glia, subsequently graft the cultured cells, and eventually remove only the grafted neurons, leaving grafted non-neuronal cells intact. Such studies would begin to clarify the relative contribution of specific cell types responsible for graft-induced functional recovery.

Previous work by Lund and colleagues (Backes et al., 1990) and Freed and colleagues (Freed et al., 1988) demonstrated the usefulness of graft removal via immunological rejection. Grafts of embryonic retina to rat mesencephalon have been shown to undergo immune rejection following a skin graft to the host. Such rejection produces a systemic immune response, total graft rejection, and profound infiltration by inflammatory cells. This response takes place for all regions of the grafted tissue. Advantages of PL in removing or damaging grafted cclls include the ability to remove only a geographically localized subset of 

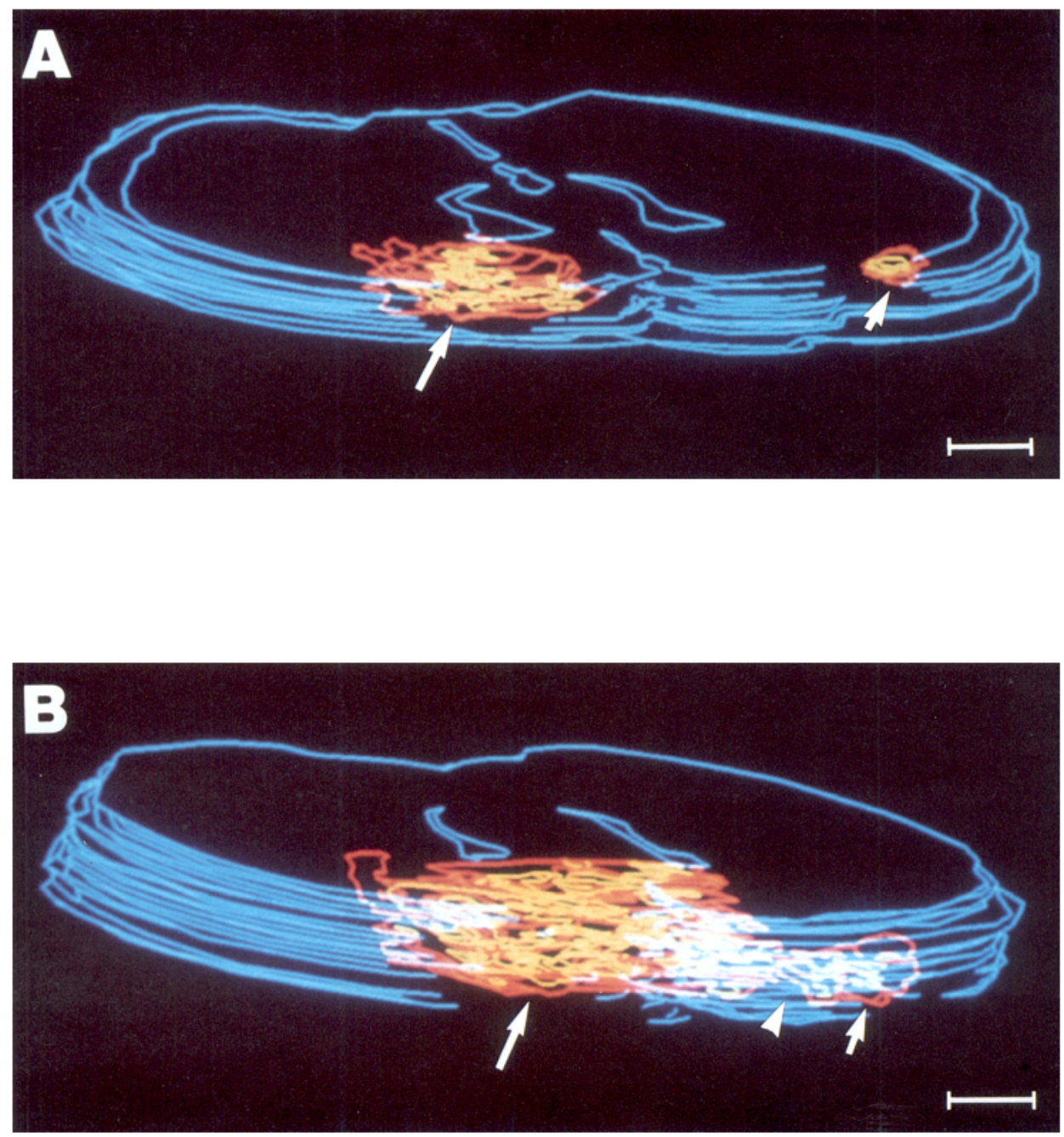

Figure 4. 3-D computer reconstructions from serial coronal sections of brains at $7 \mathrm{~d}(A)$ and $14 \mathrm{~d}(B)$. Labeled control NB grafts are on the left (long arrows), and laser-illuminated NB grafts are on the right (short arrows). $A$, Typical appearance at $7 \mathrm{~d}$, with vastly larger volume on the control side. Internal graft contours within the control grafts represent areas of acellularity or necrosis not included in quantitative volume measurements. $B$, Typical appearance at $14 \mathrm{~d}$, showing the control graft expanding across the midline (arrowhead) and compressing the ventricular system. The control grafts consisted primarily of anaplastic NB cells with active mitoses, while laser-illuminated grafts were composed of degenerated NB "ghost" cells and inflammatory cells, with virtual elimination of anaplastic NB cells. Scale bars, $1 \mathrm{~mm}$.

the grafted population and the ability to induce graded levels of cellular injury. One could transplant neurons to two anatomically distinct sites and then selectively remove only one transplant population. This type of experiment would begin to address whether such grafted cells are acting in a simple paracrine fashion (e.g., as cellular neurotransmitter pumps) or whether true anatomical integration is necessary to produce recovery.

Our present results also demonstrate the possibility of selectively targeting neuronal subpopulations or isolated nuclei in vivo for laser lesioning. We have recently shown that injections of similar particles conjugated with carbachol into a cholinoceptive area within cat pontine tegmentum retrogradely labeled a distributed neuronal network responsible for REM sleep induction (Quattrochi et al., 1989). Neurons within such projecting CNS networks would become labeled via retrograde transport following in vivo injections of LNDS particles containing a fluorochrome and chlorin $e_{6}$ at a distant site. These labeled neurons would then be potential targets for removal by externally applied, unfocused laser illumination within geographically defined zones. All neuronal populations projecting to an area would become labeled after injecting such particles into a common terminal field of a widely distributed neuronal network. Each subpopulation of neurons could be lesioned selectively and individually in the widely distributed network via relative geographic localization of exposure to laser illumination; intermixed neurons, axons, glia, and connective tissue would remain undamaged. This selective lesioning of distributed neuronal networks may allow a new level of precision in "dissecting" elements of functional CNS anatomy, not possible with other methods. Applications toward models of selective neuronal degeneration will also be possible using subpopulation specific cellular lesions. Future investigations using such selectively lesioned models as hosts for neuronal transplantation may allow significant control over both the host and graft cellular and structural conditions.

\section{References}

Anderson RR, Parrish JA (1981a) The optics of human skin. J Invest Dermatol 77:13-19.

Anderson RR, Parrish JA (1981b) Microvasculature can be selectively damaged using dye lasers: a basic theory and experimental evidence in human skin. Lasers Surg Med 1:263-276.

Anderson RR, Parrish JA (1983) Selective photothermolysis: precise microsurgery by selective absorption of pulsed radiation. Science 220: 524-527.

Backes MG, Lund RD, Lagenaur CF, Kunz HW, Gill TJ (1990) Cellular events associated with peripherally induced rejection of mature neural xenographs placed into neonatal rat brains. J Comp Neurol $15: 428-437$. 
Bently D, Caudy M (1983) Pioneer axons lose directed growth after selective killing of guidepost cells. Nature 304:62-65.

Berns MW (1984) Hematoporphyrin derivative photoradiation therapy of cancer. New York: Liss.

Bjorklund A, Stenevi U (1984) Intracerebral neural implants: neural replacement and reconstruction of damaged circuitries. Annu Rey Neurosci 7:279-308.

Bjorklund A, Stenevi U, Dunnett SB, Gage FH (1982) Cross-species neural grafting in a rat model of Parkinson's disease. Nature 298: $652-654$.

Brundin P, Nilsson OG, Strecker RE, Lindvall O, Astedt B, Bjorklund A (1986) Behavioral effects of human fetal dopamine neurons grafted in a rat model of Parkinson's disease. Exp Brain Res 65:235-240.

Cohan CS, Hadley RD, Kater SB (1982) "Zap axotomy": growth of single axons induced by localized fluorescent dye irradiation. Soc Neurosci Abstr 8:84.11.

Colombo JA, Almeida JI, Molina S (1987) In vitro culture and labeling of neural cell aggregates followed by transplantation. Exp Neurol 98: 606-615.

Coulombe JN, Bronner-Fraser M (1986) Cholinergic neurons acquire adrenergic neurotransmitters when transplanted into an embryo. $\mathrm{Na}$ ture 324:569-572.

Eclancher F, Ramirez JJ, Stein DG (1985) Neonatal brain damage and recovery: intraventricular injection of NGF at time of injury alters performance of active avoidance. Dev Brain Res 19:227-235.

Eisen JS, Pike SH, Debu B (1989) The growth cones of identified motoneurons in embryonic zebrafish select appropriate pathways in the absence of specific cellular interactions. Neuron 2:1097-1104.

Emmett CJ, Lawrence JM, Seeley PJ (1988) Visualization of migration of transplanted astrocytes using polystyrene microspheres. Brain Res 447:223-233.

Freed WJ (1983) Functional brain tissue transplantation: reversal of lesion-induced rotation by intraventricular substantia nigra and adrenal medulla grafts with a note on intracranial retinal grafts. Biol Psychiatry 18:1205-1267.

Freed WJ, Dymecki J, Poltorak M, Rodgers CR (1988) Intraventricular brain allografts and xenografts: studies of survival and rejection with and without systemic sensitization. Prog Brain Res 78:233-241.

Gage FH, Bjorklund A, Stenevi U, Dunnett SB, Kelly PAT (1984a) Intrahippocampal septal grafts ameliorate learning impairments in aged rats. Science 225:533-536.

Gage FH, Dunnett SB, Brundin P, Isacson O, Bjorklund A (1984b) Intracerebral grafting of embryonic neural cells into the adult host brain: an overview of the cell suspension method and its application. Dev Neurosci 6:137-151.

Gage FH, Wolff JA, Rosenberg MB, Xu L, Yee J-K, Shults C, Freidmann T (1987) Grafting genetically modified cells to the brain: possibilities for the future. Neuroscience 23:795-807.

Gibbs RB, Cotman CW (1987) Factors affecting survival and outgrowth from transplants of entorhinal cortex. Neuroscience 21:699706

Goetz CG, Olanow CW, Koller WC, Penn RD, Cahill D, Morantz R, Stebbins G, Tanner CM, Klawans HL, Shannon KM, Comella CL, Witt T, Cox C, Waxman M, Gauger L (1989) Multicenter study of autologous adrenal medullary transplantation to the corpus striatum in patients with advanced Parkinson's disease. N Engl J Med 320: 337-341

Goldberg WJ, Bernstein JJ (1988) Fetal cortical astrocytes migrate from cortical homografts throughout the host brain and over the glia limitans. J Neurosci Res 20:38-45.

Hibbard E, Erlich D (1982) Laser-induced defects of retinal development in chick embryos. Neurosci Lett 34:221-226.

Kamo H, Kim SU, McGeer PL, Araki M, Tomimoto H, Kimura H (1987) Transplantation of cultured human spinal cord cells into the rat motor cortex: use of Phaseolus vulgaris leucoagglutinin as a cell marker. Neurosci Lett 76:163-167.

Kater SB, Hadley RD (1982) Video monitoring of neuronal plasticity. Trends Neurosci 5:80-82.

Katz LC, Burkhalter A, Dreyer WJ (1984) Fluorescent latex microspheres as a retrograde neuronal marker for in vivo and in vitro studies of visual cortex. Nature 310:498-500.

Kromer LF (1987) Nerve growth factor treatment after brain injury prevents neuronal death. Science 235:214-216.
Kromer LF, Bjorklund A, Stenevi U (1983) Intracephalic embryonic neural implants in the adult rat brain. I. Growth in mature organization of brainstem, cerebellar, and hippocampal implants. J Comp Neurol 21 8:433-459.

Lee MH, Rabe A, Wang P (1988) Fetal neocortical transplants improve spatial behavior in old micrencephalic rats. Soc Neurosci Abstr 14 308.8

Macklis JD, Madison R (1985) Unfocused laser illumination kills dyetargeted mouse neurons by selective photothermolysis. Brain Res 359 158-165.

Macklis JD, Quattrochi JJ (1991) Restricted diffusion and stability of carbachol-fluorescent nanospheres in vivo. Neuro Report, in press.

Madison R, Macklis JD (1989) Noninvasive laser lesioning of neuronal subpopulations. In: Short course 2 syllabus, Selective lesioning in the nervous system (Cotman CW, ed), pp 42-52. Washington, DC: Society for Neuroscience.

Madison RD, Macklis JD, Frosch MP (1988) Noninvasive laser microsurgery selectively damages labeled mouse neurons: dependence on incident laser dose and absorption. Brain Res 445:101-110.

Madison R, Macklis JD, Thies C (1990) Selective uptake and transport of latex nanospheres containing fluorescent dyes and active agents into mouse neurons in vitro and in vivo. Brain Res 522:90-98.

Miller JP, Selverston AI (1979) Rapid killing of single neurons by irradiation of intracellularly injected dye. Science 206:702-704.

Nietro-Sampedro M, Whittemore SR, Needels DL, Larson J, Cotman CW (1984) The survival of brain transplants is enhanced by extracts from injured brain. Proc Natl Acad Sci USA 81:6250-6254.

Oseroff AR, Ohuoha D, Hasan T, Bommer JC, Yarmush ML (1986) Antibody targeted photolysis: selective photodestruction of human T-cell leukemia cells using monoclonal antibody-chlorin $e_{6}$ conjugates. Proc Natl Acad Sci USA 83:8744-8748.

Quattrochi JJ, Madison R, Sidman RL, Kljavin I (1987) Colloidal gold fluorescent microspheres: a new retrograde marker visualized by light and electron microscopy. Exp Neurol 96:219-224.

Quattrochi JJ, Mamelak AN, Madison RD, Macklis JD, Hobson JA (1989) Mapping neuronal inputs to REM sleep induction sites with carbachol-fluorescent microspheres. Science 245:984-986.

Raisman G, Morris RJ, Zhou C-F (1987) Specificity in the reinnervation of adult hippocampus by embryonic hippocampal transplants. Prog Brain Res 71:325-333.

Raper JA, Bastiani MJ, Goodman CS (1984) Pathfinding by neuronal growthcones in grasshopper embryos. IV. The effects of ablating the $A$ and $P$ axons upon the behavior of the $G$ growthcone. $J$ Neurosci $4: 2329-2345$.

Reier PJ (1985) Neural tissue grafts and repair of the injured spinal cord. Neuropath Appl Neurobiol 11:81-104.

Rosenberg MB, Friedmann T, Robertson RC, Tuszynski M, Wolff JA Breakefield XO, Gage FH (1988) Grafting genetically modified cells to the damaged brain: restorative effects of NGF expression. Science 242:1575-1577.

Rosenstein JM (1987) Neocortical transplants in the mammalian brain lack a blood-brain barrier to macromolecules. Science 235:772-774.

Sladek JR, Redmond DE, Collier TJ, Haber SN, Elsworth JD, Deutch AY, Roth RH (1987) Transplantation of fetal dopamine neurons in primate brain reverses MPTP induced parkinsonism. Prog Brain Res 71:309-323.

Sotelo C, Alvarado-Mallart RM (1986) Growth and differentiation of cerebellar suspensions transplanted into the adult cerebellum of mice with heterodegenerative ataxia. Proc Natl Acad Sci USA 83:11351139.

Sotelo C, Alvarado-Mallart RM (1987) Reconstruction of the defective cerebellar circuitry in adult Purkinje cell degeneration mutant mice by Purkinje cell replacement through transplantation of solid embryonic implants. Neuroscience 20:1-22.

Stanfield BB, O'Leary DDM (1985) Fetal occipital cortical neurons transplanted to the rostral cortex can extend and maintain a pyramidal tract axon. Nature 313:135-137.

Wan S, Parrish JA, Anderson RR, Madden M (1981) Transmittance of non-ionizing radiation in human tissues. Photochem Photobiol 34 $679-681$. 